\section{Iron Content of Mammalian Breast Milk: Measurements in the Rat and in a Marsupial}

LITTLE attention has been paid to the physiology of iron transfer through the mammary gland into milk, although a considerable amount of work has been done on absorption through the intestinal epithelium and on transfer from mother to foetus through the placenta. Direct measurements of the iron content of milk have mostly been confined to man and dairy animals. The average concentration of iron is approximately $0.5 \mu \mathrm{g} / \mathrm{ml}$. in both human and bovine milk $^{1}$. This value is lower than the levels of plasma iron in the respective species. In rat milk, on the other hand, a mean iron concentration of $7 \mu \mathrm{g} / \mathrm{ml}$., a figure which is higher than plasma iron values, was reported by Cox and Mueller ${ }^{2}$.

During the course of work by us and others in this Department, on various aspects of iron metabolism in lactating animals and in the developing young, we have accumulated a large series of measurements on milk iron in the laboratory rat and in the quokka, a macropod marsupial indigenous to Western Australia ${ }^{3}$. The results of these studies will be reported in detail elsewhere. It seems, however, appropriate at this stage to direct attention to certain similarities between the two animal species in respect of the iron content of milk.

Briefly, in both rat and quokka the iron content of milk assumes values considerably higher than the plasma iron and there is in both species a clear pattern of change in milk iron content with different stages of lactation. The iron in rat milk is highest at the beginning of lactation and then diminishes gradually (Fig. 1). It is of some interest to note that in the series represented in the graph the mean iron concentration taken over the whole period of lactation agrees well with the figure of $7 \mu \mathrm{g} / \mathrm{ml}$. given by Cox and Mueller. In the quokka, where the young are confined to the marsupial pouch and to an exclusive milk diet for nearly six months of their extra-uterine

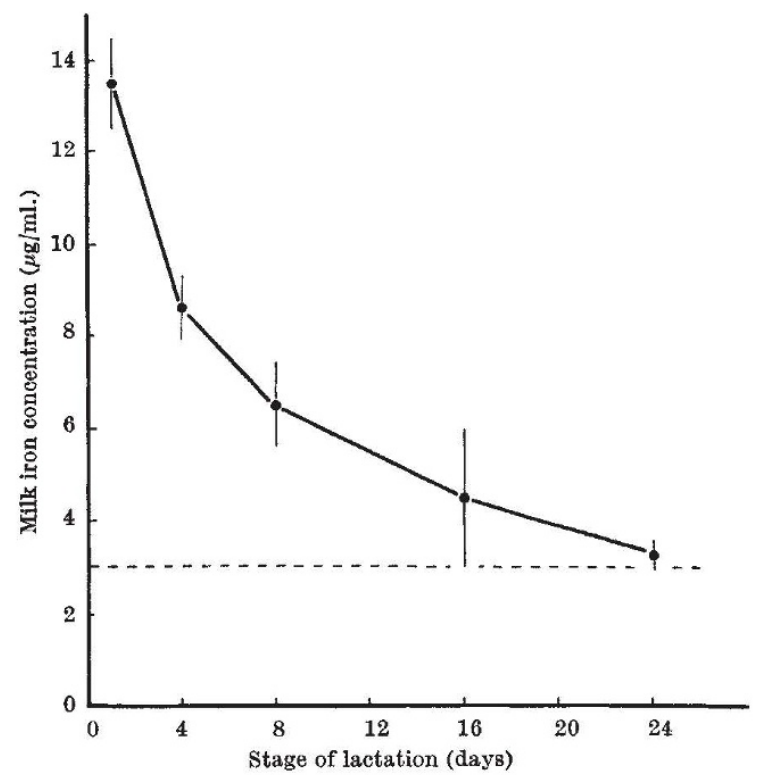

Fig. 1. Iron in rat milk. Each plot with a vertical bar represents the mean and its standard error for a group of 16 rats, except on day 1 , where the group consisted of 9 rats. The horizontal lactating rats

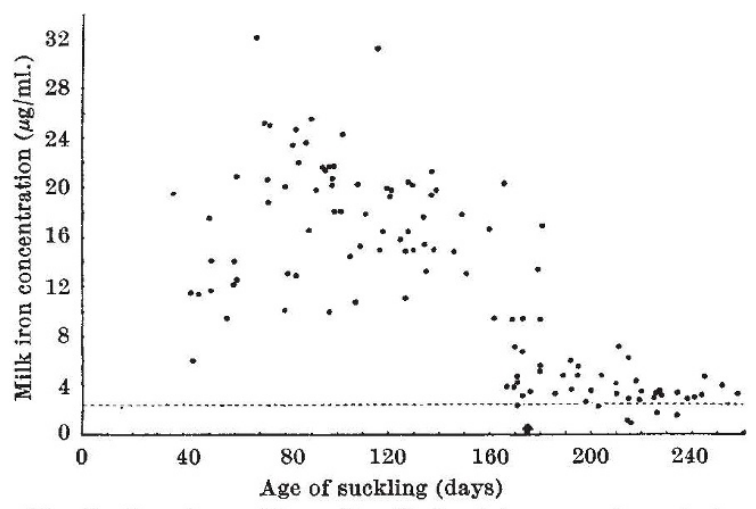
Fig. 2. Iron in quokka milk. Each plot represents a single plasma iron concentration in lactating quokkas. The arrow on the abscissa indicates the average age at which weaning begins. The age of the young was estimated from measurements of physical characters as described by Shield and Woolley (ref. 7)

life, milk iron remains consistently high throughout this period but a drop in the concentration occurs with the onset of weaning (Fig. 2).

A physiological mechanism capable of concentrating iron into the milk is of obvious biological significance in those mammals the young of which are born relatively 'immature'. In the young quokka, the hæmoglobin concentration of blood rises from approximately $9 \mathrm{~g} / 100 \mathrm{ml}$. at one month of age to $13 \mathrm{~g} / 100 \mathrm{ml}$. at six months. The amount of nonhæmoglobin storage iron accumulated in the liver of six-month-old animals is greater than the corresponding fraction in maternal livers, though the weight of these young is only one-sixth to one-seventh that of the adult females (KaIdor, to be published).

In the case of the new-born rat, which grows faster and suckles for a much shorter period than the young quokka, it is more difficult to give a clear interpretation of the physiological significance of high maternal milk iron values. The suckling rat becomes anæmic before weaning ${ }^{4}$ and this anæmia has been attributed to the inability of erythropoietic mechanisms to match the rate of body growth ${ }^{5}$. It has been shown that the iron content per unit body weight is also reduced at the time of onset of weaning ${ }^{6}$, but in our own series young rats accumulated iron in proportion to their body weight throughout the suckling period (Ezekiel and Morgan, $J$. Physiol., in the press). We are, as yet, unable to explain this difference in results.

Work is now in progress in this Department on the mechanism of iron transfer from plasma to milk. It is hoped that such studies may contribute to the general problem of iron transfer across cellular barriers.

This work was supported by the National Health and Medical Research Council of Australia and the Medical Research Grants Fund, University of Western Australia.

\section{KALDOR} ERIC EzeKIEL

Department of Physiology,

University of Western Australia, Nedlands.

${ }^{1}$ Underwood, E. J., Trace Elements in Human and Animal Nutrition, (Academic Press, New York, 1956).

${ }^{2}$ Cox, W. M., jun., and Mueller, A. J., J. Nutrition, 13, 249 (1937).

${ }^{3}$ Hodgkin, E. P., and Sheard, K. (edit.), J. Roy. Soc. West Austral., 48, Pt. 3, 65 (1959).

- Josephs, H. W., Medicine, 15, 307 (1936)

- Garcia, J. F., Amer. J. Physiol., 180, 19 (1957).

- McCance, R. A., and Widdowson, E. M., J. Physiol., 112, 450 (1951).

" Shield, J. W., and Woolley, Patricia, Austral. J. Zool., 9, 14 (1961). 